\title{
Prediction of the main cutting force in longitudinal turning of AISI D6 tool steel bars by applying full and fractional experimental design
}

\author{
Kyriaki-E. Aslani ${ }^{1,2}$, John D. Kechagias ${ }^{1}$, Nikolaos A. Fountas ${ }^{3}$, Nektarios Vidakis ${ }^{4}$, \\ Angelos Koutsomichalis ${ }^{5}$, Dimitrios E. Manolakos ${ }^{6}$ and Nikolaos M. Vaxevanidis ${ }^{3, *}$ \\ ${ }^{1}$ General Department, University of Thessaly, Larissa, Greece. \\ ${ }^{2}$ Department of Mechanical Engineering, University of West Attica, Athens, Greece. \\ ${ }^{3}$ Department of Mechanical Engineering Educators, School of Pedagogical and Technological \\ Education (ASPETE), Amarousion, Greece \\ ${ }^{4}$ Department of Mechanical Engineering, Hellenic Mediterranean University, Iraklion Crete, Greece \\ ${ }^{5}$ Department of Aeronautical Studies, Hellenic Air-Force Academy, Dekelia Air Force Base, Greece \\ ${ }^{6}$ School of Mechanical Engineering, National Technical University of Athens (NTUA), Athens, \\ Greece
}

\begin{abstract}
This investigation concerns the cutting force magnitude during turning of AISI D6 tool steel using both Taguchi Experimental Design (TED) and full factorial design (FFD). Three main cutting parameters namely spindle speed, feed rate and depth of cut were considered as the cutting parameters, each one having three levels, while the cutting force $(\mathrm{Fc})$ was selected as the machinability process output. The full factorial design of the 27 (33) experiments was splitted in three sub-arrays, each one having 9 experiments. These three sub-arrays were orthogonal and were treated as Taguchi L9 orthogonal arrays. The performance of the FFD and each TED was analysed using stem-and-leaf plots, box plots, as well as analysis of means (ANOM) and analysis of variance (ANOVA). The results obtained indicate the suitability of all proposed experimental designs for machinability studies.
\end{abstract}

\section{Introduction}

Turning is a type of material processing operation where a cutting tool is used to remove unwanted material to produce a desired product and it is generally performed on either conventional or computer numerically controlled (CNC) lathes. In recent decades, considerable improvements were achieved in turning, enhancing machining of difficult-tocut materials and resulting in improved machinability in terms of surface finish and cutting force [1]. Cutting force estimation and modeling are of major importance for the metal cutting theory. There is a great number of inter-related parameters that affect the cutting

\footnotetext{
*Corresponding author: vaxev@aspete.gr
} 
forces, such as operational parameters, cutting tool geometrical characteristics and coatings, etc; therefore the development of a proper model is a quite difficult task [2]. Although that an enormous amount of related data is available in machining handbooks, the majority of these data attempt to define the relationship between only a few of the various cutting parameters whilst keeping the other parameters fixed [3]. ANNs are one of the most powerful computer modeling techniques, currently being used in many fields of engineering for modeling complex relationships which are difficult to describe with physical models. ANNs have been extensively applied in modeling many metal-cutting operations either conventional (turning, milling, grinding) or unconventional (EDM, AWJM, etc) [3-7]. This study evaluates the full factorial design (FFD) and the Taguchi experimental design (TED) during longitudinal turning of tool steel material. In this first attempt only cutting force is evaluated.

\section{Experimental details}

The experimental data were extracted from a previous investigation regarding the evaluation of machinability in turning of AISI D6 tool steel, applying a feed forward back propagation (FFBP) artificial neural network (ANN); see [7]. In this study, only the data concerning the main cutting force of the AISI D6 tool steel are utilized. The cutting parameters are spindle speed (n) in rpm, feed rate (s) in $\mathrm{mm} / \mathrm{rev}$ and depth of cut (a) in $\mathrm{mm}$, each one having three levels. The original experimental results as reported in the corresponding $\mathrm{L}_{27}$ array can be found in [7]. Turning experiments were conducted using a Kern Modell D18L conventional lathe. The cutting tool was a SECO ${ }^{\circledR}$ coated tool insert, coded as TNMG 160404 - MF2 with TP 2000 coated grade. Sverker-3® tool steel was used as a cutting material. It is a high-carbon (2.05\%), high-chromium (12.7\%) tool steel alloyed with tungsten $(1.1 \%)$ identical to AISI-D6 grade with hardness $240 \mathrm{HB}$. All test materials were supplied as $\varnothing 45 \mathrm{~mm}$ bars.

\section{Results and Discussion}

In this investigation, Taguchi experimental design (TED) and full factorial design (FFD) are compared with the use of analysis of means (ANOM) and analysis of variance (ANOVA). Both methologies are applied in order to determine the factors which affect the main cutting force Fc. Minitab 17 Statistical Software was utilized for the statistical analysis.

\subsection{Full Factorial Array}

In the present investigation, the original $\mathrm{L}_{27}$ array is considered as the full factorial array [7]. Analysis of Variance (ANOVA) is tabulated in Table 1, while Analysis of Means diagram is presented in Figure 1. The parameter values which minimize the cutting force are speed $=850 \mathrm{rpm}$, feed $=0.06 \mathrm{~mm} / \mathrm{rev}$ and depth of cut $=0.5 \mathrm{~mm}$. In case of ANOVA, F and $\mathrm{P}$ values and contribution rate should be considered for determining the parameters which affect a variable. High F-values and contribution rate imply significance; so, do small $\mathrm{P}$-values $(\mathrm{P}<0.05)$. According to the above, depth of cut $(\mathrm{a})$ is the cutting parameter which affects more the cutting force $(\mathrm{F}=72.89, \mathrm{P}=0.000, \mathrm{CR}=67.45 \%)$, followed by feed rate $(\mathrm{s})$ which is almost as important as feed of rate in terms of influence $(\mathrm{F}=24.12, \mathrm{P}$ $=0.000, \mathrm{CR}=22.32 \%)$ and by speed $(\mathrm{n})$ which doesn't affect $\mathrm{Fc}(\mathrm{F}=1.06, \mathrm{P}=0.365, \mathrm{CR}$ $=0.98 \%$ ). 


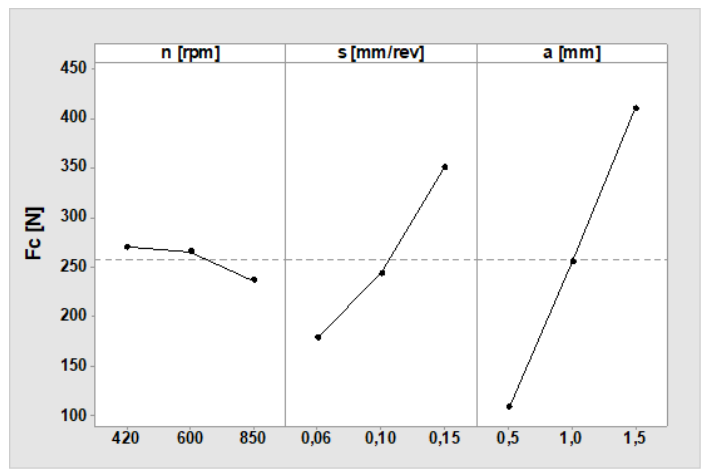

Fig. 1. ANOM for main cutting force Fc.

Table 1. ANOVA for main cutting force Fc.

\begin{tabular}{|c|c|c|c|c|c|c|}
\hline Source & DF & Adj SS & Adj MS & F-Value & P-Value & Contribution Rate [\%] \\
\hline $\mathrm{n}[\mathrm{rpm}]$ & 2 & 5915 & 2957 & 1.06 & 0.365 & 0.98 \\
\hline $\mathrm{s}[\mathrm{mm} / \mathrm{rev}]$ & 2 & 134430 & 67215 & 24.12 & 0.000 & 22.32 \\
\hline $\mathrm{a}[\mathrm{mm}]$ & 2 & 406287 & 203143 & 72.89 & 0.000 & 67.45 \\
\hline Error & 20 & 55743 & 2787 & - & - & 9.25 \\
\hline Total & 26 & 602375 & - & - & - & - \\
\hline
\end{tabular}

\subsection{L9 (1) Array}

The first $\mathrm{L}_{9}$ Orthogonal Array for the main cutting force $\mathrm{Fc}$ is tabulated in Table 2. As indicated by ANOM diagram (Fig. 2) the parameters that minimize the cutting force are: speed $=600 \mathrm{rpm}$, feed $=0.06 \mathrm{~mm} / \mathrm{rev}$ and depth of cut $=0.5 \mathrm{~mm}$. ANOVA (Table 3) revealed that depth of cut $(\mathrm{a})$ is the dominant parameter $(\mathrm{F}=6.87, \mathrm{P}=0.127, \mathrm{CR}=$ $70.78 \%)$, followed by feed rate $(\mathrm{s})(\mathrm{F}=1.72, \mathrm{P}=0.367, \mathrm{CR}=17.76 \%)$ and by speed $(\mathrm{n})(\mathrm{F}$ $=0.11, \mathrm{P}=0.898, \mathrm{CR}=1.17 \%$ ).

Table 2. L9 (1) experimental array.

\begin{tabular}{|c|c|c|c|c|}
\hline & $\mathbf{n}[\mathbf{r p m}]$ & $\mathbf{s}[\mathbf{m m} / \mathbf{r e v}]$ & $\mathbf{a}[\mathbf{m m}]$ & $\mathbf{F c}[\mathbf{N}]$ \\
\hline 1 & 420 & 0.06 & 1 & 188 \\
\hline 2 & 420 & 0.1 & 1.5 & 452 \\
\hline 3 & 420 & 0.15 & 0.5 & 146 \\
\hline 4 & 600 & 0.06 & 1.5 & 284 \\
\hline 5 & 600 & 0.1 & 0.5 & 96 \\
\hline 6 & 600 & 0.15 & 1 & 364 \\
\hline 7 & 850 & 0.15 & 1.5 & 536 \\
\hline 8 & 850 & 0.06 & 0.5 & 138 \\
\hline 9 & 850 & 0.1 & 1 & 184 \\
\hline
\end{tabular}

Table 3. ANOVA for main cutting force Fc.

\begin{tabular}{|c|c|c|c|c|c|c|}
\hline Source & DF & Adj SS & Adj MS & F-Value & P-Value & Contribution Rate [\%] \\
\hline $\mathrm{n}[\mathrm{rpm}]$ & 2 & 2216 & 1108 & 0.11 & 0.898 & 1.17 \\
\hline $\begin{array}{c}\mathrm{s} \\
{[\mathrm{mm} / \mathrm{rev}]}\end{array}$ & 2 & 33731 & 16865 & 1.72 & 0.367 & 17.76 \\
\hline $\mathrm{a}[\mathrm{mm}]$ & 2 & 134411 & 67205 & 6.87 & 0.127 & 70.78 \\
\hline Error & 20 & 19555 & 9777 & - & - & 10.29 \\
\hline Total & 26 & 189912 & - & - & - & - \\
\hline
\end{tabular}




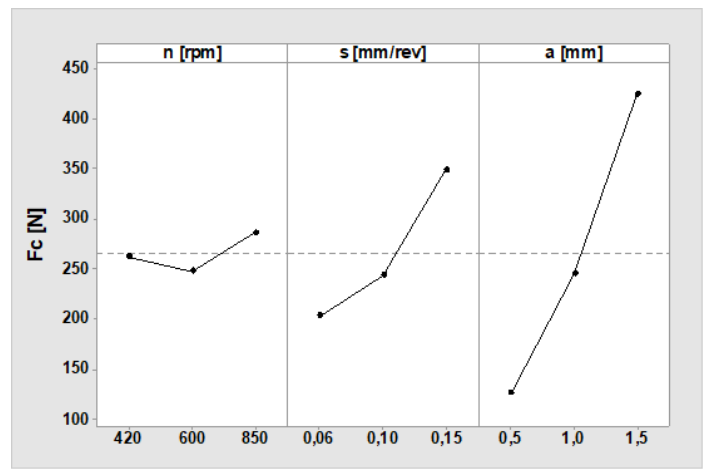

Fig. 2. ANOM for main cutting force Fc.

\subsection{L $\mathrm{L}_{9}(2)$ Array}

The second $\mathrm{L}_{9}$ Orthogonal Array for the main cutting force Fc is presented in Table 4. ANOM diagram (Fig. 3) illustrates that the parameters which minimize the cutting force are: speed $=850 \mathrm{rpm}$, feed $=0.06 \mathrm{~mm} / \mathrm{rev}$ and depth of cut $=0.5 \mathrm{~mm}$. ANOVA (Table 5) revealed that depth of cut (a) is the dominant parameter $(\mathrm{F}=28.97, \mathrm{P}=0.033, \mathrm{CR}=$ $63.41 \%)$, followed by feed rate $(\mathrm{s})(\mathrm{F}=13.26, \mathrm{P}=0.07, \mathrm{CR}=29.01 \%)$ and by speed $(\mathrm{n})(\mathrm{F}$ $=2.46, \mathrm{P}=0.289, \mathrm{CR}=5.39 \%$ ).

Table 4. $\mathrm{L}_{9}$ (2) experimental array.

\begin{tabular}{|c|c|c|c|c|}
\hline & $\mathbf{n}[\mathbf{r p m}]$ & $\mathbf{s}[\mathbf{m m} / \mathbf{r e v}]$ & $\mathbf{a}[\mathbf{m m}]$ & $\mathbf{F c}[\mathbf{N}]$ \\
\hline 1 & 420 & 0.06 & 1.5 & 260 \\
\hline 2 & 420 & 0.1 & 0.5 & 112 \\
\hline 3 & 420 & 0.15 & 1 & 376 \\
\hline 4 & 600 & 0.06 & 0.5 & 72 \\
\hline 5 & 600 & 0.1 & 1 & 272 \\
\hline 6 & 600 & 0.15 & 1.5 & 536 \\
\hline 7 & 850 & 0.06 & 1 & 160 \\
\hline 8 & 850 & 0.1 & 1.5 & 344 \\
\hline 9 & 850 & 0.15 & 0.5 & 136 \\
\hline
\end{tabular}

Table 5. ANOVA for main cutting force Fc.

\begin{tabular}{|c|c|c|c|c|c|c|}
\hline Source & DF & Adj SS & Adj MS & F-Value & P-Value & Contribution Rate [\%] \\
\hline $\mathrm{n}[\mathrm{rpm}]$ & 2 & 9632 & 4816 & 2.46 & 0.289 & 5.39 \\
\hline $\mathrm{s}[\mathrm{mm} / \mathrm{rev}]$ & 2 & 51915 & 25957 & 13.26 & 0.070 & 29.01 \\
\hline $\mathrm{a}[\mathrm{mm}]$ & 2 & 113419 & 56709 & 28.97 & 0.033 & 63.41 \\
\hline Error & 20 & 3915 & 1957 & - & - & 2.19 \\
\hline Total & 26 & 178880 & - & - & - & - \\
\hline
\end{tabular}




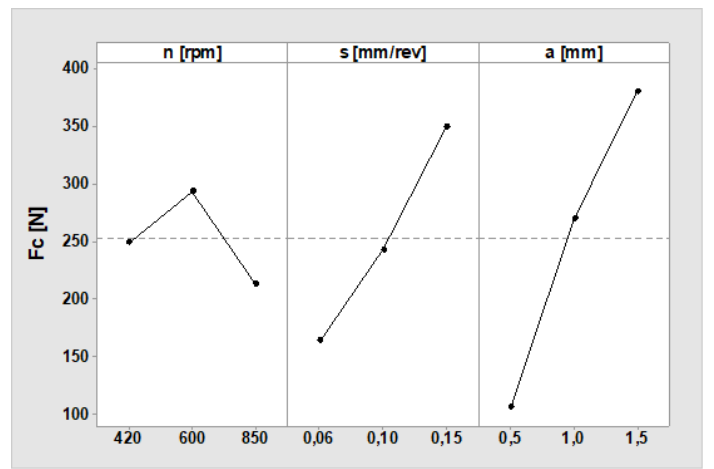

Fig. 3. ANOM for main cutting force Fc.

\subsection{L (3) Array}

The third $\mathrm{L}_{9}$ Orthogonal Array for the main cutting force Fc can be found in Table 6 . ANOM diagram (Fig. 4) shows that the parameters which minimize the cutting force are: speed $=850 \mathrm{rpm}$, feed $=0.06 \mathrm{~mm} / \mathrm{rev}$ and depth of cut $=0.5 \mathrm{~mm}$. ANOVA (Table 7) revealed that depth of cut (a) is the dominant parameter $(\mathrm{F}=26.75, \mathrm{P}=0.036, \mathrm{CR}=$ $70.53 \%)$, followed by feed rate $(\mathrm{s})(\mathrm{F}=8.26, \mathrm{P}=0.108, \mathrm{CR}=21.76 \%)$ and by speed $(\mathrm{n})(\mathrm{F}$ $=1.92, \mathrm{P}=0.342, \mathrm{CR}=5.07 \%$ ).

Table 6. L9 (3) experimental array.

\begin{tabular}{|c|c|c|c|c|}
\hline & $\mathbf{n}[\mathbf{r p m}]$ & $\mathbf{s}[\mathbf{m m} / \mathbf{r e v}]$ & $\mathbf{a}[\mathbf{m m}]$ & $\mathbf{F c}[\mathbf{N}]$ \\
\hline 1 & 420 & 0.06 & 0.5 & 68 \\
\hline 2 & 420 & 0.1 & 1 & 246 \\
\hline 3 & 420 & 0.15 & 1.5 & 584 \\
\hline 4 & 600 & 0.06 & 1 & 184 \\
\hline 5 & 600 & 0.1 & 1.5 & 428 \\
\hline 6 & 600 & 0.15 & 0.5 & 152 \\
\hline 7 & 850 & 0.06 & 1.5 & 256 \\
\hline 8 & 850 & 0.1 & 0.5 & 56 \\
\hline 9 & 850 & 0.15 & 1 & 320 \\
\hline
\end{tabular}

Table 7. ANOVA for main cutting force Fc.

\begin{tabular}{|c|c|c|c|c|c|c|}
\hline Source & DF & Adj SS & Adj MS & F-Value & P-Value & Contribution Rate [\%] \\
\hline $\mathrm{n}[\mathrm{rpm}]$ & 2 & 11793 & 5896 & 1.92 & 0.342 & 5.07 \\
\hline $\mathrm{s}[\mathrm{mm} / \mathrm{rev}]$ & 2 & 50652 & 25326 & 8.26 & 0.108 & 21.76 \\
\hline $\mathrm{a}[\mathrm{mm}]$ & 2 & 164118 & 82059 & 26.75 & 0.036 & 70.53 \\
\hline Error & 20 & 6134 & 3067 & - & - & 2.64 \\
\hline Total & 26 & 232697 & - & - & - & - \\
\hline
\end{tabular}




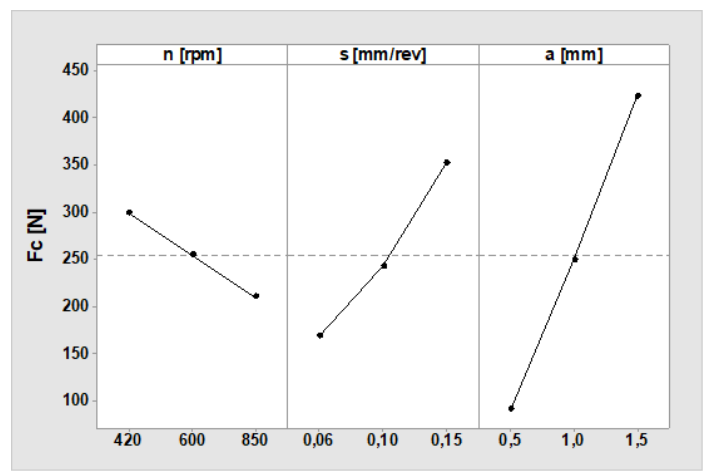

Fig. 4. ANOM for main cutting force Fc.

\section{Conclusions}

Data analysis applied on the above two experimental design methodologies and the following conclusions are revealed:

- The cutting force ANOM diagrams have the same trend lines as it concerns feed rate (s) and depth of cut (a). These two parameters are the most important for cutting forces during turning and the results are in accordance with the orthogonal cutting theory. When these two parameters are increased, the cutting force increased too.

- The contribution of the cutting parameters in cutting force are: (i) depth of cut: FFD (67.45\%); TED (70.53\%, 63.41\%, 70.53\%), (ii) feed rate: FFD (22.32\%); TED $(17.76 \%, 29.01 \%, 21.76 \%)$ and (iii) speed: FFD (0.98\%); TED (1.17\%, 5.39\%, 5.07\%)

The above analysis approve that the two experimental design methodologies have very similar results and can be safely concluded that TED methodology is as reliable as FFD when used for cutting force predictions and data analysis in turning of tool steel materials.

\section{References}

1. N.M. Vaxevanidis, N. Galanis, G.P. Petropoulos, N. Karalis, P. Vasilakakos and J. Sideris, Surface Roughness Analysis in High Speed-Dry Turning of Tool Steel, Proc. ESDA2010 (paper ESDA2010-24811)

2. G. Boothroyd and W. Knight, Fundamentals of Machining and Machine Tools, CRC Press, (2005)

3. T. Szecsi, J. Mater. Process. Technol., 92-93, (1999)

4. G. Dini, CIRP Ann., 46, 2 (1997)

5. T.M.A. Maksoud, M.R. Atia and M.M. Koura, Mach. Sci. Technol. 7, 3 (2003)

6. E.O. Ezugwu, D.A. Fadare, J. Bonney, R.B. Da Silva and W.F. Sales, Int. J. Mach. Tools Manuf., 45 (2005)

7. N.M Vaxevanidis, J.D. Kechagias, N.A. Fountas, D.E. Manolakos "Three component cutting force system modeling and optimization in Turning of AISI D6 tool steel using design of experiments and Neural Networks" Proc. WCE 2013, 1 (2013) 